\title{
Virtual Capacity Building for International Research Collaborations in Times of COVID-19 and \#Flygskam
}

OPEN ACCESS

Edited by:

Muddassar Sarfraz,

Nanjing University of Information Science and Technology, China

Reviewed by:

Rita Berger,

University of Barcelona, Spain

Hamdi Chtourou,

University of Sfax, Tunisia

${ }^{*}$ Correspondence:

Isabell Richter

isabel.richter@plymouth.ac.uk

Specialty section:

This article was submitted to

Organizational Psychology,

a section of the journal

Frontiers in Communication

Received: 22 May 2020 Accepted: 29 December 2020

Published: 29 January 2021

Citation:

Richter I, Gabe-Thomas E, Maharja C, Nguyen TH, Van Nguyen Q, Praptiwi R and Pahl S (2021) Virtual Capacity Building for International Research Collaborations in Times of COVID-19

and \#Flygskam.

Front. Commun. 5:562828.

doi: 10.3389/fcomm.2020.562828

\author{
Isabel Richter ${ }^{*}$, Elizabeth Gabe-Thomas ${ }^{2}$, Carya Maharja ${ }^{3}$, Thu Ha Nguyen ${ }^{4}$, \\ Quyen Van Nguyen ${ }^{5,6}$, Radisti Praptiwi ${ }^{3,7}$ and Sabine Pahl ${ }^{1,8}$
}

${ }^{1}$ School of Psychology, Faculty of Health, University of Plymouth, Plymouth, United Kingdom, ${ }^{2}$ Plymouth Marine Laboratory, Plymouth, United Kingdom, ${ }^{3}$ Centre for Sustainable Energy and Resources Management, Universitas Nasional, Jakarta, Indonesia, ${ }^{4}$ Faculty of Social Work, Hanoi National University of Education, Hanoi, Vietnam, ${ }^{5}$ Faculty of Biology, Hanoi National University of Education, Hanoi, Vietnam, ${ }^{6}$ Center for Environmental Research and Education (CERE), Hanoi National University of Education, Hanoi, Vietnam, ${ }^{7}$ Department of Biotechnology, Universitas Esa Unggul, Jakarta, Indonesia, ${ }^{8}$ Urban and Environmental Psychology Group, Institute for the Psychology of Cognition, Emotion and Methods, Faculty of Psychology, University of Vienna, Vienna, Austria

In the wake of the current global pandemic, international travel is restricted. This poses substantial challenges for research relationships aiming to build capacity and foster cocreation to achieve the Sustainable Development Goals, where global collaboration and communication is paramount. This is especially challenging when it comes to interactive dialogues that go beyond the typical one-way structure of online learning. Considerations on structural, technical and behavioral levels are needed to not only deal with these challenges but rather to take advantage of the new situation. This commentary outlines the lessons learned from an internationally operating project, co-developed to cope with travel restrictions. We discuss implications for future reduction of international travel to reduce carbon in the context of climate change.

Keywords: sustainability, co-creation, global relationships, capacity building, virtual communication

\section{INTRODUCTION}

The Sustainable Development Goals (SDGs) address global challenges including climate change, equality, education and health for peace and prosperity. To create and implement evidence-based solutions, we need effective and targeted capacity building firmly embedded within best research practice (Division for Sustainable Development Goals, 2015). Such research capacity must be built on close communication and interaction across international borders. However, researchers are experiencing substantial challenges in delivering these activities due to current mind shifts toward criticizing and shaming airplane travel (Flygskam movement) in combination with travel restrictions due to the coronavirus disease (COVID-19) (WHO, 2020). This is an opportune moment to develop best practice for virtual interactions, which will not only facilitate working under the current circumstances but will allow us to reduce the carbon emissions generated by international projects in the future (Achten et al., 2013; Verplanken and Roy, 2016). The present commentary highlights practices, challenges and suggestions related to capacity building we undertook within the Global Challenges Research Fund's Blue Communities project (www.bluecommunities.org/Home) where researchers had to rapidly adjust delivery for participants from four countries from a face-toface capacity-building program to a virtual format.

Capacity building is defined as "building abilities, relationships and values that will enable organizations, groups and individuals to improve their performance and achieve their development 


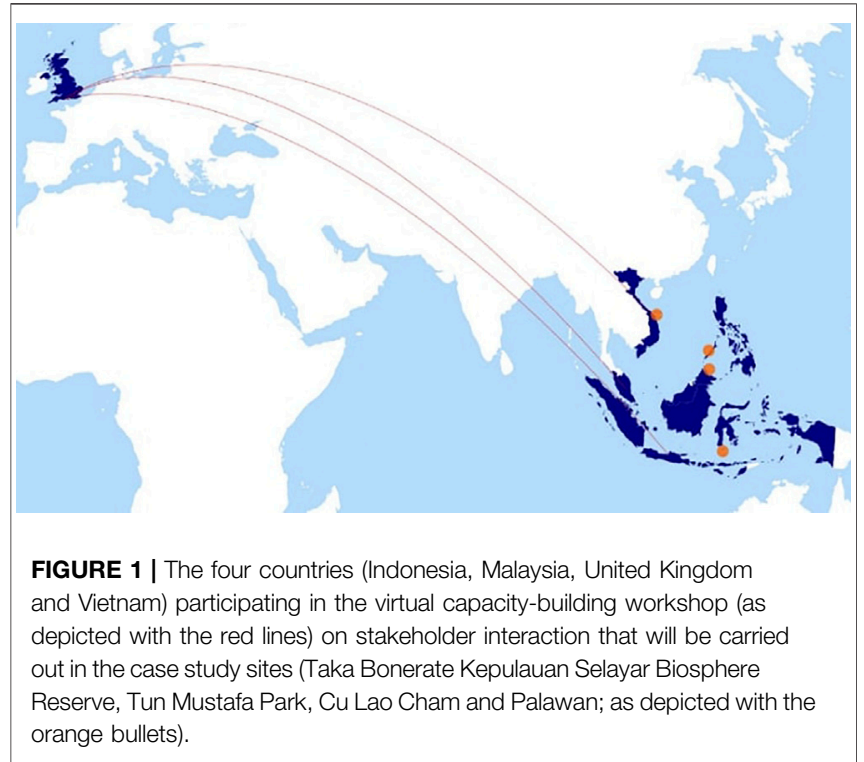

objectives" (UNEP, 2002, p. 11). Whilst developing countries are often perceived as the receivers of capacity building from more developed countries, it is important to recognize the bidirectionality of this relationship, as researchers from both sides have valuable knowledge, experience and skills that can be transferred. For the benefits of capacity building to reach all participants co-creation is key (multiple actors are equally empowered and develop pathways to achieve mutual outcomes) to the process. Capacity building and co-creation typically involve a high degree of skill-based and practical training, requiring a high degree of interactivity, which traditionally takes place face-to-face. The current restrictions in international travel as well as the goal to cut down on carbon emissions challenge us to create ways of building capacity via virtual channels.

Current practices of virtual interaction include online learning, online conferences, webinars, livestreams as well as virtual meetings. While some of those practices (e.g., webinars) emphasize knowledge transfer and are often not interactive, others can be interactive (e.g., virtual meetings) but this potential interactivity is not yet fully exploited. The academic community has responded quickly to the challenges of delivering remote teaching. Although the teaching can be highly interactive, they are rarely co-created and often simply replace traditional formats of talks and presentations. Projects striving for mutual capacity building and co-creation (Chemi and Krogh, 2017) are in need of innovative ways to deliver the bidirectional transfer of knowledge, the acquisition of new techniques as well as providing room for flexibility and discussion.

The Global Challenges Research Fund (GCRF) Blue Communities Project connects researchers from five countries (Indonesia, Malaysia, the Philippines, the United Kingdom and Vietnam) with the aim of building capacity and delivering research on sustainable management of coastal communities and marine ecosystems in Southeast Asia. Like thousands of research teams around the world, Blue Communities is facing the challenge to keep meeting the project's goals without the benefits of face-to-face interactions during joint field visits (Holton, 2001). Considering the current situation we are forced to explore how we can build trust and dialogue, deliver international capacity building and advance research activities through virtual interactions.

Here, we describe lessons learned from a capacity building workshop originally intended to take place in Indonesia with participants from four countries (Figure 1). Due to the outbreak of the COVID-19 virus, the workshop was held remotely. The aim of this workshop was to build local capacity by demonstrating and co-creating various methods of running stakeholder workshops in the respective coastal communities. This type of capacity building requires a highly interactive exchange as the learning process is multidirectional. In our case, the United Kingdom partners were supposed to deliver methods training in social and behavioral science. The three case study partners from Indonesia, Vietnam and Malaysia were to contribute with their expertize in ecology, fisheries and marine biology and with in-depth information about the selected sites. The ideal outcome of the workshop would be a co-developed project plan with methods flexibly adapted to each site.

With the aim to welcome the challenge and to deliver highquality outputs according to the funder's standards and our personal project goals, we had to adapt across three dimensions: behavioral, structural and technical. Behavioral adaptation covers all conscious amendments we identified to optimize interpersonal communication, group leadership and engagement. Structural and technical adaptation encompasses the consideration of different time zones, internet connectivity and additional equipment. In the following section, we present our identified key considerations across these three dimensions. Subsequently, we are going on to discuss the advantages and disadvantages of the virtual format, ending with some recommendations. Our insights are by no means meant to be exhaustive and can be extended or transferred to other virtual workshops requiring a high level of engagement and interaction.

\section{BEHAVIORAL, STRUCTURAL AND TECHNICAL CONSIDERATIONS}

\section{The Importance of Icebreakers}

Getting to know each other or building new rapport might be neglected when connecting online from multiple locations. We claim that with the added physical distance, it is even more important to establish personal connections between participants to make up for the lack of non-verbal communication. Some but not all partners in our workshop had already established working relationships. To build rapport we asked everyone joining the meeting to describe him- or herself in three short sentences including the professional background and expertize as well as a personal fun fact.

\section{Facilitating Communication}

We found that communication can be challenging in virtual settings, especially with poor connection. Therefore, we used 
multiple routes of communication. These routes involved preworkshop email exchange to develop the agenda and the workshop aims, collect topics to cover and to discuss a code of conduct. During the workshop we used a chat box within the software for all participants to ask questions. Workshop leaders took turns to monitor the chat box. In addition, we used email and phone conversations after the workshop to cover additional topics that could not be covered or required more expansion to provide closure.

We found having at least two people present in the same room per location was helpful, if this is possible given regulations on social distancing. This helps to stay on top of the multiple pathways of communication, share responsibilities and avoid the likely exhaustion that will occur during virtual capacity building (Schoenenberg et al., 2014). That said, we still experienced virtual capacity building as exceptionally draining for all parties involved, listening or presenting, which makes it absolutely necessary to have regular breaks (Connelly, 2018). For this reason, we split the originally planned one-day workshop into three consecutive sessions, in an attempt not to overload workshop leaders or participants. This also considered time differences between countries.

\section{Communication Fine Tuning}

Many subtle interactions that enable a face-to-face workshop cannot be directly transferred to virtual capacity building. In order to effectively communicate, cooperate and empathize with our colleagues we needed to find creative solutions. Compared to face-to-face workshops we cannot get an accurate feel if our partners are still motivated, tired or confused. Especially for the presenter it can be a daunting experience not to receive the verbal and non-verbal reassurance that would be implicit in any face-to-face interaction. Research has shown that very small delays (above $1200 \mathrm{~ms}$ ) in visuo-audio feedback can lead to negative perceptions of participants on a personal level (Schoenenberg et al., 2014). It is crucial to create a perception of social presence despite the physical distance created by online communication (Aragon, 2003). Establishing a combination of information transfer, group work, result demonstration, discussion and breaks allows all participants to actively engage using the various channels of communication, and to efficiently switch between individual listening, individual responding, joint practicing, social discussing and recovering (Anzai and Simon, 1979; Hiltz et al., 2000; Yang and Liu, 2004; Chang et al., 2014).

\section{Time Management}

This brings us to the importance of time management. We experienced that virtual capacity building required more time than standard capacity building. This is due to materials that have to be adapted or prepared, the need for more breaks during the workshop, but also potential time lags between the sending and the receiving party making it necessary to repeat sequences more frequently. The Blue Communities capacitybuilding program had to be planned across three time zones with up to eight hour time difference. Ideally, workshops like this would take place during working hours for all parties involved. In reality, global interactions force us to be flexible. In our case, this meant that some teams connected during early mornings or late evenings. Collectively deciding on a time schedule that best suits the majority of participants is crucial.

\section{Attitude and Motivation}

When capacity building takes place remotely, a higher level of commitment is required than would be necessary for a face-toface workshop (Mroz et al., 2019). We tried to accomplish this by carrying a very positive, energized mind-set and by creating an inclusive meeting atmosphere as recommended by Schneider et al. (2018). To benefit from the combination of direct and indirect interactions, wherever possible people from the same location should gather physically in one room and interact directly whilst interacting with the groups in other locations virtually. This helps to mix the virtual interaction with immediate collaboration but social distancing rules might mean participants have to connect separately, an additional strain to connectivity.

\section{Connectivity Equipment and Platform}

Obvious technical and structural requirements include a good internet connection, meeting rooms and relevant equipment. A stable internet connection can be problematic, especially in developing countries or remote areas as was the case for the Blue Communities project. We experienced interruptions during the meeting, difficulties in uploading and downloading materials as well as impeded functionality of different communication channels.

We established a set of instructions for 1) very strong bandwidth: all partners share their video and audio settings 2) partially problematic bandwidth: partner with problematic bandwidth to turn off video, all turn off audio apart from when they speak 3) problematic bandwidth: all partners turn off video and audio settings with the exception of the current speaker. This code of conduct was familiar to all parties involved, leading to fluent communication across conditions.

An important factor is the use of a platform that enables sharing screen, text chatting and uploading documents and pictures. These functions are essential for a high level of interactivity, as is the use of a good quality camera by the workshop leaders. We found a movable camera with zooming and focusing function to be particularly useful for ensuring interactive materials (flip charts and post-it notes) were legible on screen. We also found microphone quality to be important as better microphones reduce communication issues due to different mother tongues.

\section{Supporting Materials}

A crucial element was the use of comprehensive supporting materials. A pre-workshop checklist was distributed to all participants. Some items might seem self-evident in the context of face-to-face workshops, but they might be forgotten in virtual interactions (e.g., flip charts and post its). We found the mixture of physical and electronic materials useful.

As an additional resource, we prepared an electronic handbook, which contained a literature list, methods and data 
analysis instructions. This helped to reduce the reliance purely on audio/video information. The scope of the handbook went beyond the content of the workshop itself and complemented other materials such as PowerPoint slides, which all were adapted to the new purpose of virtual capacity building. We identified visuals a key form of communication as they can be understood across language barriers and despite poor audio connections (Tufte, 2003; Susskind, 2005).

\section{DISCUSSION}

In this last section, we will discuss how we found ourselves benefitting from this novel situation as well as struggling with challenges we did not fully overcome. We will conclude with the main lessons learned to facilitate current and future projects relying on remote capacity building.

\section{Finding Advantages in the Crisis}

As a side effect of restricted travel, remote capacity building can reduce travel related carbon emissions beyond the pandemic. In addition, remote capacity building gives rise to more advantages than just carbon savings.

\section{Strains on Resources and Health}

Online capacity building workshops are a less costly way to achieve international skills and knowledge transfer than faceto face interactions. Costs for traveling, accommodation, meeting rooms and catering are reduced drastically. Along with the financial savings comes the time saved that is usually spent on planning, layovers, environmental adaptation and jetlag. This means that not only are virtual meetings more cost-effective but they also take less toll on our physical and mental wellbeing. We remain located in our familiar environment and time zone, which is in line with our evolutionary circadian rhythm (Minors et al., 1986; Reilly et al., 2005; Srinivasan et al., 2010). At the same time, we need to be aware that the rise of virtual meetings, home office confinement and movement restrictions during a pandemic can have negative effects on our physical and mental health (for overviews see Ammar et al., 2020a; Ammar et al., 2020b; Ammar et al., 2020c). Bentlage et al. (2020) as well as Chtourou et al. (2020) provide a range of evidence-based, practical recommendations of how to mitigate the psychosocial strain during home confinement, for example by remaining physically active.

\section{Equality}

Despite the aim to bridge the distance imposed by the virtual connection, there might also be advantages coming with the distance itself. People who struggle with face-to-face interactions might be able to communicate better without the presence of direct cues used to detect potential negative feedback from others (Stritzke et al., 2004). Similarly, virtual capacity building facilitates the inclusion of people for whom participating under traditional circumstances would be difficult or impossible (Pearson and Koppi, 2002). However, we need to be aware of setup adaptation for participants with sensory or cognitive impairments. This includes the appropriate use of visuals, the availability of additional supporting resources, the awareness of individual limitations and an active communication network between participants for mutual support. We also need to be aware that the intensified use of virtual technology bears the risk of causing further inequalities due to differences in accessibility of such technology and opportunity to acquire relevant skills. Cultural and gender related stereotypes are potentially less problematic for virtual collaborations than they would be in face-to-face interactions. There may be a reduced risk of cultural or religious offense due to inappropriate clothing, catering or schedules, especially if the workshop is co-created.

\section{Disadvantages to Overcome}

Despite the potential benefits of remote capacity building, we think it is important to acknowledge some disadvantages that we were unable to overcome in the limited time we had available during this crisis. We invite suggestions for strategies to help overcome these remaining barriers.

\section{Language Barriers}

Some challenges like cultural and gender-related roles and stereotypes seem to be diminished whereas some other challenges seem to be enhanced in remote communication. Language barriers are always a challenge within international collaboration. However, understanding each other and adapting to different linguistic varieties might be even more difficult in virtual settings and lead to disruptions or compromised team functioning (Neeley et al., 2012; Klitmøller and Lauring, 2013). On the individual level, uncertainty and diminished comprehension can lead to confusion or frustration and in the worst case to the refusal of active engagement (Barner-Rasmussen and Björkman, 2007). These challenges might lead to attempts to catch up with the content in parallel or being prone to external distractions. Overcoming these challenges takes patience by all team members, the provision of excellent supplementary material as well as the willingness to answer questions continuously.

\section{Participant-To-Participant Interaction}

While adequate trainer-participant interactions are relatively easy to realize and are perceived as normal and necessary, this may not be the case for participant-to-participant interaction. In our case, there has been an active dialogue between the United Kingdom and the partners from each country in South East Asia, but almost no interaction between Vietnam, Malaysia and Indonesia. For the main purpose of mutual capacity building, which should involve networking between all participants and learning from others' best practice, participant-to-participant interaction is indispensable. Actively encouraging participant groups to communicate with each other during designated tasks could overcome this challenge.

Considering the disadvantages, the delivery of virtual capacity building may not be appropriate for all training contents which still require direct physical interactions like for example complex field work activities or the handling of tools. When there is choice, the advantages and disadvantages of virtual and ordinary capacity building need to be carefully considered before making the decision to travel or not. 


\section{KEY TAKEAWAY MESSAGES}

We need to question our existing practices and norms when it comes to global collaboration for capacity building and create new, innovative measures and strategies. Based on our three-day experience of virtual capacity building we have identified several key lessons that can apply for similarly structured activities.

Firstly, it is important to keep the dialogue active despite the obvious convenience of a one-way communication. An interactive dialogue is the key to the co-creation of project plans and enables us to go beyond one-way training and toward mutual capacity building.

Along the same lines, the workshop preparation should involve backup plans, allowing for the unexpected to happen. This flexibility is best realized through active communication between all partners, continuous co-creation and meticulous workshop development.

Thirdly, we need to make it clear to ourselves what the potential advantages and disadvantages of holding a virtual capacity building workshop are, prior to the process itself. This is to acknowledge the limitations inherent in the approach, which may call adoptions of specific structural, technological and behavioral adaptations.

Despite its non-physical nature, we feel that our virtual workshop did reduce the geographical difference amongst us. Not only by co-delivering our workshop but also by jointly

\section{REFERENCES}

Achten, W. M. J., Almeida, J., and Muys, B. (2013). Carbon footprint of science: more than flying. Ecol. Indic. 34, 352-355. doi:10.1016/j.ecolind. 2013.05.025

Ammar, A., Brach, M., Trabelsi, K., Chtourou, H., Boukhris, O., Masmoudi, L., et al. 2020a). Effects of COVID-19 home confinement on eating behaviour and physical activity: results of the ECLB-COVID19 international online survey. Nutrients 12 (6), 1583. doi:10.3390/nu12061583

Ammar, A., Chtourou, H., Boukhris, O., Trabelsi, K., Masmoudi, L., Brach, M., et al. (2020b). COVID-19 home confinement negatively impacts social participation and life satisfaction: a worldwide multicenter study. Int. J. Environ. Res. Public Health 17 (17), 6237. doi:10.3390/ijerph17176237

Ammar, A., Mueller, P., Trabelsi, K., Chtourou, H., Boukhris, O., Masmoudi, L., et al. (2020c). Psychological consequences of COVID-19 home confinement: the ECLB-COVID19 multicenter study. PloS One 15 (11), e0240204. doi:10. 1371/journal.pone.0240204

Anzai, Y., and Simon, H. A. (1979). The theory of learning by doing. Psychol. Rev. 86 (2), 124. doi:10.1037/0033-295x.86.2.124

Aragon, S. R. (2003). Creating social presence in online environments. New Dir. Adult Cont. Educ. 2003 (100), 57-68. doi:10.1002/ace.119

Barner-Rasmussen, W., and Björkman, I. (2007). Language fluency, socialization and inter-unit relationships in Chinese and Finnish subsidiaries. Manag. Organ. Rev. 3 (1), 105-128. doi:10.1111/j.1740-8784.2007.00060.x

Bentlage, E., Ammar, A., How, D., Ahmed, M., Trabelsi, K., Chtourou, H., et al. (2020). Practical recommendations for maintaining active lifestyle during the COVID-19 pandemic: a systematic literature review. Int. J. Environ. Res. Public Health 17 (17), 6265. doi:10.3390/ijerph17176265

Chang, J., Benamraoui, A., and Rieple, A. (2014). Learning-by-doing as an approach to teaching social entrepreneurship. Innovat. Educ. Teach. Int. 51 (5), 459-471. doi:10.1080/14703297.2013.785251

Chemi, T., and Krogh, L. (2017). Co-creation in higher education: students and educators preparing creatively and collaboratively to the challenge of the future. Rotterdam, Netherlands: Sense Publishers. rethinking our lessons learned for this article made us appreciate the togetherness of us as disparate workshop members striving to achieve a common aim despite the current challenges.

\section{DATA AVAILABILITY STATEMENT}

The original contributions presented in the study are included in the article, further inquiries can be directed to the corresponding author.

\section{AUTHOR CONTRIBUTIONS}

All authors jointly conceived of the presented concept. IR developed the article structure and took the lead in writing the manuscript with input and feedback from all collaborators. SP supervised the process.

\section{FUNDING}

This work has received funding in part from the Global Challenges Research Fund (GCRF) via the United Kingdom Research and Innovation (UKRI) under grant agreement reference NE/P021107/1 to the Blue Communities project.

Chtourou, H., Trabelsi, K., H'mida, C., Boukhris, O., Glenn, J. M., Brach, M., et al. (2020). Staying physically active during the quarantine and self-isolation period for controlling and mitigating the COVID-19 pandemic: a systematic overview of the literature. Front. Psychol. 11, 1708. doi:10.3389/fpsyg.2020.01708

Connelly, M. Y. (2018). A Mixed methods study of teacher burnout in online environments versus face-to-face and blended environments. Dissertation. Florida (FL): Keiser University.

Division for Sustainable Development Goals (2015). Goal 17-capacity building. Available at: https://sustainabledevelopment.un.org/sdg17 (Accessed May 6, 2020).

Hiltz, S. R., Coppola, N., Rotter, N., Turoff, M., and Benbunan-Fich, R. (2000). Measuring the importance of collaborative learning for the effectiveness of ALN: a multi-measure, multi-method approach. JALN 4 (2), 103-125. doi:10. 24059/olj.v4i2.1904

Holton, J. A. (2001). Building trust and collaboration in a virtual team. Team Perform. Manag. 7 (3/4), 36-47. doi:10.1108/13527590110395621

Klitmøller, A., and Lauring, J. (2013). When global virtual teams share knowledge: media richness, cultural difference and language commonality. J. World Bus. 48 (3), 398-406. doi:10.1016/j.jwb.2012.07.023

Minors, D. S., Scott, A. R., and Waterhouse, J. M. (1986). Circadian arrhythmia: shiftwork, travel and health. J. Soc. Occup. Med. 36 (2), 39-44. doi:10.1093/ occmed/36.2.39

Mroz, J. E., Landowski, N., Allen, J. A., and Fernandez, C. (2019). Organizational meeting orientation: setting the stage for team success or failure over time. Front. Psychol. 10, 812. doi:10.3389/fpsyg.2019.00812

Neeley, T. B., Hinds, P. J., and Cramton, C. D. (2012). The (Un) Hidden turmoil of language in global collaboration. Organ. Dynam. 41 (3), 236-244. doi:10.1016/j. orgdyn.2012.03.008

Pearson, E. J., and Koppi, T. (2002). Inclusion and online learning opportunities: designing for accessibility. RLT-J 10 (2), 17-28. doi:10.3402/rlt.v10i2.11398

Reilly, T., Waterhouse, J., and Edwards, B. (2005). Jet lag and air travel: implications for performance. Clin. Sports Med. 24 (2), 367-380. doi:10. 1016/j.csm.2004.12.004

Schneider, K., Klünder, J., Kortum, F., Handke, L., Straube, J., and Kauffeld, S. (2018). Positive affect through interactions in meetings: the role of proactive and supportive statements. J. Syst. Software 143, 59-70. doi:10.1016/j.jss.2018.05.001 
Schoenenberg, K., Raake, A., and Koeppe, J. (2014). Why are you so slow?-misattribution of transmission delay to attributes of the conversation partner at the far-end. Int. J. Hum. Comput. Stud. 72 (5), 477-487. doi:10.1016/j.ijhcs.2014.02.004

Srinivasan, V., Singh, J., Pandi-Perumal, S. R., Brown, G. M., Spence, D. W., and Cardinali, D. P. (2010). Jet lag, circadian rhythm sleep disturbances, and depression: the role of melatonin and its analogs. Adv. Ther. 27 (11), 796-813. doi:10.1007/s12325-010-0065-y

Stritzke, W. G. K., Nguyen, A., and Durkin, K. (2004). Shyness and computermediated communication: a self-presentational theory perspective. Media Psychol. 6 (1), 1-22. doi:10.1207/s1532785xmep0601_1

Susskind, J. E. (2005). PowerPoint's power in the classroom: enhancing students' self-efficacy and attitudes. Comput. Educ. 45 (2), 203-215. doi:10.1016/j. compedu.2004.07.005

Tufte, E. (2003). PowerPoint is evil. September: Wired Magazine.

UNEP (2002). Capacity Building for Sustainable Development: an overview of UNEP environmental capacity development initiatives. Available at: https://www. unenvironment.org/resources/report/capacity-building-sustainable-developmentoverview-unep-environmental-capacity (Accessed May 11, 2020).

Verplanken, B., and Roy, D. (2016). Empowering interventions to promote sustainable lifestyles: testing the habit discontinuity hypothesis in a field experiment. J. Environ. Psychol. 45, 127-134. doi:10.1016/j.jenvp.2015. 11.008

WHO (2020). Novel coronavirus (2019-nCoV) situation report-22. Available at: https://www.who.int/docs/default-source/coronaviruse/situation-reports/ 20200211-sitrep-22-ncov.pdf?sfvrsn=fb6d49b1_2 (Accessed April 7, 2020).

Yang, S. C., and Liu, S. F. (2004). Case study of online workshop for the professional development of teachers. Comput. Hum. Behav. 20 (6), 733-761. doi:10.1016/j.chb.2004.02.005

Conflict of Interest: The authors declare that the research was conducted in the absence of any commercial or financial relationships that could be construed as a potential conflict of interest.

Copyright (c) 2021 Richter, Gabe-Thomas, Maharja, Nguyen, Van Nguyen, Praptiwi and Pahl. This is an open-access article distributed under the terms of the Creative Commons Attribution License (CC BY). The use, distribution or reproduction in other forums is permitted, provided the original author(s) and the copyright owner(s) are credited and that the original publication in this journal is cited, in accordance with accepted academic practice. No use, distribution or reproduction is permitted which does not comply with these terms. 